\title{
CONFLUÊNCIAS ENTRE O FANTÁSTICO E A INQUIETUDE DO RISO
}

\section{CONFLUENCES BETWEEN THE FANTASTIC AND THE RESTLESSNESS OF LAUGHTER}

O riso sempre foi matéria de reflexão. Até hoje especula-se sobre o enigmático livro II, a parte dedicada à sátira na Poética, de Aristóteles. Como fenômeno adjacente à sátira, o riso foi indicado por Cícero para tratar de assuntos sérios. O orador Quintiliano, por exemplo, apontava a sua importância no discurso para aniquilar um adversário político. Ainda nesse sentido, ao traçar extenso material de pesquisa sobre o riso e o escárnio, Georges Minois iniciou sua introdução com uma advertência: "o riso é um caso muito sério para ser deixado para os cômicos" (2003, p.10).

Notadamente assunto respeitável, muitos trabalhos críticos se dedicaram a investigações acerca do riso. Esses estudos se ramificaram de forma multidisciplinar e alcançaram a psicologia, a filosofia, a literatura, a teologia e a sociologia, recebendo dessas áreas a mesma importância e interesse. Na filosofia, a clássica obra de Henry Bergson (1983) circunscreveu o cômico e o riso na esfera propriamente humana e dotados de função social. Como substância da condição humana, social e cultural, desde seu papel gerador da kátharsis, na Antiguidade, o riso se fortaleceu como expediente de depuração, subversão e resistência, mas foi a partir do Renascimento que a ‘teoria do riso' se expandiu.

Mikhail Bakthin (1987, p.3) destinou especial atenção ao riso popular, às manifestações do cômico, ao grotesco e à cultura do humor na Idade Média e no Renascimento. De acordo com o autor, essa natureza específica do riso e do humor, apesar de possuir relevada importância, foi analisada estreitamente sob uma ótica deformada, uma vez que ao riso e ao cômico medieval, muitas vezes, foram destinadas noções alheias a sua graça popular, imprimindo-lhe feições da cultura e da estética burguesa moderna. A fim de revelar esse potencial do cômico e do carnavalesco, o estudo de Bakthin se centra na interpretação da sátira política e grotesca de François Rabelais, obra que fixará mudança significativa na história do riso.

Apesar da diversidade de obras destinadas a decifrar o riso, Minois assinalou que ele é ambíguo e esconde seus mistérios. As faculdades do riso oscilam da agressividade ao tom 
amigável, de caráter multiforme, ele assumiu as formas "da ironia, do humor, do burlesco, do grotesco (...) Pode expressar tanto a alegria pura quanto o triunfo maldoso, o orgulho ou a simpatia. É isso que faz sua riqueza e fascinação ou, às vezes, seu caráter inquietante" (MINOIS, 2003, p. 11).

É justamente esse caráter ambíguo, inquietante e misterioso que nos permite considerar com mais atenção o vínculo entre o riso e o fantástico. Ao se deter no estudo da arte e da literatura fantásticas, Louis Vax (1970, p. 14-15) destina um tópico para avaliar a relação entre o fantástico e o humor. Para o autor, à primeira vista, o humor e a ironia são incompatíveis com o fantástico, seriam aparentemente tão excludentes como a água e o fogo; ao descrever esse sistema, exemplifica: se rirmos de uma história apavorante, o medo imediatamente se dissipa, logo, o elemento insólito fica comprometido. Entretanto, Vax pondera que as coisas não são simples; ao contrário, são bem complexas quando tratamos da coexistência desses dois componentes no mesmo espaço. Em diferentes situações, o riso pode estar a serviço de um mecanismo de defesa, uma espécie de vingança contra a invasão do medo: "existe nesse riso algo de agressivo e vingador" (VAX, 1970, p.14). Seguindo esse raciocínio, Bergson assinalou que "riso é, antes de tudo, um castigo. Feito para humilhar, deve causar à vítima dele uma impressão penosa" (1983, p.92).

Focando especificamente nessa imponderável relação, o pesquisador francês Georges Desmeules publicou a obra La littérature fantastique et le spectre de l'humour. O autor (1997, p. 25) apontou um viés incomum da literatura fantástica ao reconhecer o potencial humorístico - o "espectro do humor" - que nela pode se manifestar em maior ou menor grau. Essa convicção se funda em virtude da ambiguidade inerente ao próprio discurso fantástico. Se a condição para a efetivação da fantasticidade situa-se no confronto entre duas realidades irredutíveis, esse mesmo paradoxo pode igualmente servir à produção do humor. No humor, assim como no fantástico, o efeito esperado se revela a partir de um conflito entre duas instâncias: significante e significado; real e irreal.

Foi intencionando ampliar o debate entre o fantástico e o riso que surgiu a ideia deste dossiê: convidar pesquisadores brasileiros e estrangeiros a refletir sobre essa face pouco explorada da ficção fantástica. Dadas as características da chamada aberta, este número da Revista Graphos contempla onze textos que têm em comum a percepção do fantástico e do maravilhoso atravessada pelo riso, pelo cômico, pelo grotesco e por feições literárias congêneres. 
O texto que abre esta edição dedica-se justamente à análise do cruzamento entre um clássico tema fantástico, a morte, e o discurso humorístico. Nesse entrelace, Carolina de Aquino Gomes, analisa a forma inovadora na constituição da obra As intermitências da morte, de José Saramago, bem como a transgressão duplamente operada no romance, tanto pela linguagem parodística quanto pela desconstrução do real. O riso sempre encontrou campo fértil para se proliferar em narrativas sérias e a autora destaca esta presença nas três últimas obras de Saramago, incluindo a que escolheu para analisar. Gomes destaca que, em As intermitências da morte, a metaficção presente na obra amplia a possibilidade de se vislumbrar um discurso paródico, o que possibilita uma aproximação, ao contrário do título do livro, sugerindo uma descontinuidade entre vida e morte. Segundo a autora, a aproximação entre a narrativa fantástica e o discurso humorístico possibilita uma "transgressão, seja da linguagem ou do real". Tal perspectiva constrói uma leitura do romance de José Saramago que, "tal qual sua morte-personagem, fala-nos a sério, mesmo quando nos faz rir, e nos convida a uma reflexão sobre a morte e o morrer na contemporaneidade".

O princípio da narrativa fantástica brasileira se faz presente neste dossiê em dois estudos: de Danglei Castro Pereira e de Greicy Pinto Bellin; James Remington Krause. Ambos trazem para a discussão dois autores - Álvares de Azevedo e Machado de Assis - que figuram entre os nomes mais comumente aludidos pela crítica literária a um ciclo de narrativas que contribuiu e abriu caminhos à posterior maturação do Fantástico no Brasil. O texto de Pereira expõe como Álvares de Azevedo utiliza aspectos como o grotesco, o riso e o estranho para construir a atmosfera fantástica na obra Noite na taverna.

A opção pelo estudo da obra de Azevedo se deu pela possibilidade de abordagem de traços do real e sua manipulação em direção ao sobrenatural. Segundo o autor, Azevedo mobiliza o elemento sobrenatural para apontar para a transcendência ao real no momento de construção do ficcional. E é por meio dessa transcendência que o riso e o fantástico se apresentam na obra analisada.

Bellin e Krause desenvolvem um olhar sobre o conto "O capitão Mendonça", de Machado de Assis, narrativa em que o cientificismo é visto à luz da desconfiança, como é característico na obra do autor. Uma das formas de se desconfiar dessa lógica é adotando uma construção textual-discursiva que se desenvolva nos moldes do modo fantástico. Os autores indicam que o texto machadiano analisado é dos mais contundentes no que diz respeito a essa crítica ao cientificismo e ao positivismo. Para tal crítica se efetivar, os autores lançam mão de 
uma reflexão sobre o conceito de gênero, que auxilia na representação da figura feminina. Esse olhar contribui para uma disrupção com um contexto sociocultural que se utilizava de um aparato tecnológico, como o folhetim, para publicações voltadas àquela mulher que Eric Hobsbawn indica como um "anjo do lar", ou seja, uma figura que, nas palavras dos autores, coloca a mulher como "um ser doce, assexuado e submisso, alguém que deveria zelar pelo bem-estar de sua família, representação esta frequente na literatura oitocentista”.

No mesmo texto, encontramos a informação de que havia, à época, uma patrulha ideológica "estabelecida a partir das representações femininas e masculinas nas narrativas". Tal policiamento, para acentuar o caráter machista da sociedade, nos mostra que, para além do modo fantástico, a distância temporal torna a remissão a esses preceitos algo digno da fantasia, o que, infelizmente, ocorre de maneira premente em nossa sociedade até os dias atuais. Esses preceitos, vinculados até hoje a uma lógica pseudocientífica, são tema da análise empreendida por Bellin e Krause. Desta forma, o adultério é tratado de modo que recorra "ao modo fantástico para exercer críticas em relação à apropriação da ciência no contexto brasileiro [...] e em relação à moralidade que envolvia a traição feminina [...]”. Com essa perspectiva, o texto mescla às reflexões sobre gênero, adicionado ao modo fantástico, uma crítica ao cientificismo.

Também surpreendente, para não dizer fantástico, com todos os sentidos que a palavra pode adquirir, é o fato de um autor como Felisberto Hernández quase não ter espaço na crítica literária, ainda que figure ao lado de Jorge Luís Borges e Macedônio Fernández como precursor de configurações de escrita do modo fantástico na literatura rio-platense. É exatamente nesse o esforço de maior visibilidade que está o mérito do texto de Amanda Brandão Araújo Moreno. Além disso, a autora pontua que "um breve levantamento da fortuna crítica desse autor revelará uma ênfase no estudo da linguagem por ele empregada, apontando para seu caráter único, raro, peculiar, inusual, inquietante", o que o configura, como um membro da "constelação de renovadores", conforme indica Ángel Rama. Segundo Moreno, Felisberto Hernández atinge a potência do modo fantástico "através do recurso ao lúdico e ao humor e sua associação ao inquietante, ao insólito e ao fantástico, que o autor uruguaio alicerça a estrutura de sua narrativa”, além de uma poderosa linguagem capaz de zoomorfizar o humano e/ou antropomorfizar o animal.

Amanda Moreno aborda de forma ampla o humor produzido pelas narrativas fantásticas de Felisberto Hernández, independente da fase da obra do autor uruguaio. Neste 
sentido, conforme a autora pontua, "o texto aponta para a ação do escritor, no reiterado trabalho de tessitura textual, associado ao caráter imprevisível do espontâneo, do inconsciente. Somado a isso, sobrevém a vida autônoma que o texto adquire tanto enquanto é escrito como depois que ganha o público. O nível de intervenção da consciência atua na dimensão do mistério”. Por fim, a leitura proposta por Moreno é uma reflexão permeada pelo riso, pelo humor, pelo fantástico, pelo grotesco e pelo horror em obras em prosa de um autor, Felisberto Hernández, que dialoga constantemente com a cultura popular.

Em diálogo com essa lógica cultural de matiz mais popular, o artigo de João Paulo Fernandes, "O rapto do riso em $O$ Pavão misterioso", oferece uma importante contribuição sobre como uma das mais representativas obras da cultura popular, O Pavão misterioso, transcende o gênero literário normalmente categorizado para ser analisado à luz dos elementos fantásticos e da presença do humor neles contidos. A análise destaca o trânsito entre o clássico e o contemporâneo que uma obra da cultura popular possibilita. Além disso, essa abertura se dá, também, numa relação tensa entre o risível e o não risível heterogeneizada pela manifestação do fantástico na obra.

$O$ romance do Pavão Misterioso, produção cordelística, carrega outras heterogeneidades para "raptar o riso" e/ou "metamorfosear o humor". Nessa obra, tal metamorfose se dá, segundo Fernandes, através de um riso diferente daquele com o qual estamos acostumados no cordel, afinal "é comum que o humor na literatura popular se revele pelo riso, provocado em disputas de cantadores, em pelejas, resultando em episódios engraçados, em que o riso 'corre frouxo', porém, contrapõe-se ao engraçado o riso que é ocultado, seja pela angústia, pela dor ou sofrimento, ou ainda pela tirania, como a ação do conde, pai de Creuza, ao mantê-la presa em seu castelo". Em perspectiva diversa, o humor e o risível se manifestam no momento crucial da narrativa: em vez de um alazão para levar o herói a salvar a princesa, um pavão inventado, "desengonçado e barulhento".

Nas fronteiras do território fantástico, o estudo de André de Sena procura revelar exemplos de metalinguagem e de metateatro irônicos, operados pelo riso nos palcos cômicos da Antiguidade. A partir disso, André de Sena traz à baila uma discussão teórica sobre a presença de uma relação profícua entre o maravilhoso, o riso e o cômico em textos filosóficos de Platão e Aristóteles, além de uma presença nos palcos de teatro da Antiguidade. Há, ainda, uma reflexão teórica sobre um texto intitulado Tractatus coislinianus, no qual se encontram discussões sobre as possíveis trocas entre o maravilhoso, o riso e o cômico. A escassez de 
textos ligados ao trágico antigo para comprovar a presença do maravilhoso (thaumaston) faz com que o olhar de Sena se volte para as comédias: "parece ser no absurdo risível da comédia, com toda a sua ousadia e metalinguagem, que o maravilhoso parece ter sido melhor admitido nos palcos antigos em termos de representação".

Daí em diante, o autor reflete sobre as comédias de Aristófanes e o caráter híbrido que essas composições possuem e o caráter de "experienciação" que essas obras proporcionam, quando "no trabalho criativo com eventos reais (que também poderiam ser manipulados ficcionalmente, segundo a teorética peripatética) ou maravilhosos e sobre-humanos, desde que respeitada uma lógica de contiguidade na história encenada, estava garantida”. Segundo o autor, a comédia antiga subverte ainda mais essa lógica ao confrontar "a verossimilhança com o avesso de si, mesma e reconfigurando o thaumaston ao lhe revelar as entranhas". A partir disso, discute as notas encontradas no já referido Tractatus coislinianus sobre a comédia, alertando-nos de que há uma possibilidade de essa obra se vincular, de alguma maneira, com a famosa parte dedicada à comédia na Poética de Aristóteles. Para encerrar, Sena assinala que “a mistura de gêneros, a iconoclastia, o inusitado, a autorreferência, o horrorífico, [...] já se moldaram nesses palcos antigos milênios antes das experimentações dos românticos e suas modalizações fantásticas, estando em suas origens conforme eles próprios asseveraram”.

Há, também, a presença de estudos sobre autores contemporâneos. O trabalho de Edna Polese trata de um texto de Socorro Acioli, mais especificamente a obra A cabeça do Santo, e analisa a presença do fantástico e do humor mesclados à religiosidade. Com maior precisão, Polese destaca que o enredo, com ambientação no sertão nordestino, mais especificamente na cidade quase abandonada de Candeia, é sobre uma "cabeça abandonada da estátua de um santo que ouve os apelos das devotas e reverbera seus pedidos a Samuel, personagem central da narrativa e desprovido de fé religiosa". O protagonista, oriundo da cidade de Juazeiro do Norte, "tinha consciência de que tudo funcionava em prol da fé dos romeiros na figura de Padre Cícero", ou seja, há uma complexa "financeirização da fé”.

Nesse contexto, a obra possui três perspectivas interpretativas: a do riso, a do fantástico e a da religiosidade popular brasileira, todas elas mescladas a uma análise da obra que nos leva a compreender a relação ambivalente da cidade com a estátua do santo decapitado. Sobre a conexão com a religiosidade, Polese assegura que a população possui "menos um exercício litúrgico que a consciência de mentalidade religiosa, antiga, exata, formal". Nesse sentido, a parte que se refere ao riso é vinculada à figura do protagonista: "a 
personagem principal, cheia de defeitos, nos encanta e nos faz rir. É o herói próximo de nós. Vive, no entanto, algo surpreendente, pouco entendido, a "'força estranha' que ele diz sentir, mas não entender".

Também embasado em textos oriundos de narrativas populares é o trabalho de Fábio Dobashi Furuzato, que aborda como os fenômenos do riso e do fantástico se manifestam em outro texto de literatura estrangeira - a obra em questão é $O$ Nariz, de Ryûnosuke Akutagawa. Inicialmente, o autor destaca a relação com o texto homônimo de Nikolai Gogol, este considerado como grotesco pelo fato de o humor se sobrepor ao fato fantástico, conforme indicação de David Roas. De maneira breve, Furuzato nos presenteia com uma síntese do enredo e seu problema maior: o nariz do protagonista era imenso, foi reduzido através de um cozimento, e as pessoas satirizavam o monge protagonista de maneira escancarada após a redução do nariz.

Antes de interpretar o conto de R. Akutagawa, Furuzato discute brevemente as tensões entre o grotesco e o fantástico a partir da relação que ambos estabelecem com o humor. É nessa perspectiva, também, que o autor embasa sua análise do conto japonês sob a ótica de articulações características do fantástico como a hesitação, o limite entre o natural e o sobrenatural, e a identificação do leitor com personagens e/ou narradores. Em outra visada, o autor desenvolve uma comparação da obra $O$ Nariz com algumas características da comédia clássica, tais como o efeito moralizante e a oposição entre protagonista e os demais personagens da obra. Em síntese, o autor nos indica que "embora este conto não se enquadre perfeitamente em nenhuma das categorias estéticas que escolhemos para analisá-lo (o fantástico, o grotesco, o cômico, [...] o conto em questão é bem mais complexo e rico do que pode parecer inicialmente".

Voltando a obras produzidas em território nacional, temos Erlândia Ribeiro da Silva e Vitor Cei Santos interpretando duas peças de Qorpo Santo sob a perspectiva da sátira, do riso e do absurdo nas peças $O$ marinheiro escritor e Um credor da fazenda nacional. Inicialmente, os autores nos fornecem elementos estéticos, como uma reforma ortográfica, e biográficos, tal qual a "monomania em escrever" que compõem a reflexão estética de Qorpo Santo. Outro elemento destacado pelos autores é a proximidade da poética fragmentária de Qorpo Santo com estratagemas surrealistas e contemporâneos. É a partir dessas reflexões que os autores chegam à reflexão desenvolvida por Albert Camus sobre o absurdo e às obras de Wladimir Propp e Georges Minois sobre o riso. 
No que diz respeito à peça $O$ marinheiro escritor, os autores indicam um caminho para a reflexão que demonstra como "essa quebra na narrativa aparecerá em outras peças, como uma forma de vazio, de não explicação ao que acontece, deixando um ar de estranheza no que se lê, mas isso logo é quebrado com mais humor e situações inusitadas", ou seja, o riso rompe (e, talvez, aprofunde) a estranheza e a absurdidade da obra. Já em Um credor da fazenda nacional, os autores pontuam momentos absurdos da burocracia institucionalizada no país, além de identificar que pessoas com ideias progressistas vão para a caridade (hospício). Então, enfrentar a absurda burocracia institucional só é possível através da comicidade.

O texto de Antônia Marly Moura Silva e Vilmária Chaves Nogueira aborda o corpo grotesco em "Bárbara”, de Murilo Rubião. Segundo as próprias autoras, o conto "“Bárbara' nos permite refletir sobre problemáticas significativas do contexto atual como, por exemplo, a imagem do corpo grotesco na literatura, o riso de horror, o disforme e a ironia sobre o padrão social de corpo imposto à mulher". Numa interpretação que olha para o corpo da personagem Bárbara, sempre descrita pelo marido, na condição de narrador, as autoras fazem um breve apanhado comparativo entre o corpo gordo, exagerado em suas formas e, portanto, grotesco, do homem e da mulher. Sistematicamente, as mulheres são punidas pelas formas exageradas de seus corpos, enquanto para os homens é sinal de saúde e pujança.

No conto de Rubião, a personagem inverte essa lógica: "a contínua deformidade da mulher que engorda e do filho que definha configura-se como antítese do padrão social e também signo de rebaixamento. (...) pode-se dizer que é uma forma da personagem tentar romper barreiras de gênero (...)”. Esse corpo monstruoso que revela e adverte, mostra-nos, segundo Silva e Nogueira, entre o possível e o impossível, um conto que "induz a uma reflexão sobre o lugar social da mulher e o seu desejo por transcendência".

Encerrando nosso dossiê especial sobre o fantástico, os estudos audiovisuais sobre o subúrbio estadunidense comparecem no texto de Pedro Artur Lauria e India Mara Martins: “O papel do humor no cinema do suburbanismo fantástico". Ao abordar a presença do humor nos sitcoms de subúrbios, Lauria e Martins esclarecem que, partir de elementos constitutivos dos cenários suburbanos e suas características em oposição aos grandes centros urbanos, elaborase um projeto ideal de lugar para a constituição de uma família. Logo, reforçam os autores, "não surpreende que nessas sitcoms o humor esteja intimamente ligado à relação familiar". A partir de algumas exemplificações, fica clara a maneira como o "humor é utilizado de maneira 
a rir das idiossincrasias e hipocrisias da própria sociedade e, mais especificamente, da classe média suburbana".

Em seguida, conhecemos as singularidades do subgênero suburbanismo fantástico, definido como um conjunto de filmes Hollywoodianos, produzidos a partir da década 1980, cujos protagonistas eram primordialmente crianças e adolescentes suburbanos envolvidos em uma situação fantástica. Em geral, o desfecho dessas aventuras era sempre construído pelo humor e pelo processo de amadurecimento dos jovens protagonistas, a exemplo de clássicos como Gremlins, E.T. - O Extraterrestre, De Volta para o Futuro e Querida, Encolhi as Crianças. Por fim, são considerados o papel mercadológico, narrativo e moral do humor nessas produções cinematográficas.

Esperamos que os textos publicados neste dossiê possam inspirar mais matérias sobre os liames entre o fantástico, o riso (humor, cômico). Por conseguinte, acreditamos que essa relação de parentesco permita extrapolar os limites do possível, expressando, pela literatura, a forma como os indivíduos se relacionam com o mundo e externalizam as camadas mais profundas de seus sentimentos.

João Pessoa, 18 de maio de 2021

Luciane Alves Santos

(UFPB)

Rogério Caetano de Almeida

(UTFPR)

Organizadores do Dossiê

\section{Referências}

BAKTHIN, Mikhail. A cultura popular na Idade Média e no Renascimento: o contexto de Fraçois Rabelais. Trad. Yara Frateschi Vieira. São Paulo: Hucitec, 1987.

BERGSON, Henry. O riso. Ensaio sobre a significação do cômico. Trad. Nathanael C. Caixeiro Rio de Janeiro: Zahar, 1983.

DESMEULES, Georges. La littérature fantastique et le spectre de l'humour. Paris:

L'instant meme, 1993. 
MINOIS, Georges. História do riso e do escárnio. Trad. Maria Elena O. Ortiz Assumpção. São Paulo: Unesp, 2003.

VAX, Louis. L'Art et la littérature fantastiques. Paris: Presses universitaires de France, 1970. 